\title{
Pelayanan Informasi Kreatif pada Daya Tarik Wisata Alam Lembah Harau, Kabupaten Lima Puluh Kota
}

\section{(The Creative Information Service at Natural Attraction of Harau Valley, Lima Puluh Kota District)}

\author{
Trisna Putra*, Waryono, Rian Surenda \\ Jurusan Pariwisata, Fakultas Pariwisata dan Perhotelan, Universitas Negeri Padang, Jl. Prof. Dr. Hamka Air Tawar, Padang, \\ Sumatera Barat 25131. \\ *Penulis Korespondensi: tputra@fpp.unp.ac.id \\ Diterima Januari 2019/Disetujui Desember 2019
}

\begin{abstract}
ABSTRAK
Signage dan peta kawasan merupakan salah satu pelayanan informasi yang penting diberikan oleh pengelola daya tarik wisata alam. Daerah tujuan wisata Lembah Harau di Kabupaten Lima Puluh Kota, Sumatera Barat, merupakan kawasan wisata alam potensial namum sangat minim dengan pelayanan informasi berupa signage dan peta kawasan. Tujuan kegiatan pengabdian ini adalah untuk memenuhi kebutuhan pelayanan informasi signage dan peta kawasan wisata. Metode yang digunakan adalah community development practice serta pendekatan partisipatif dan edukatif. Hasil kegiatan menunjukkan kelompok sadar wisata (Pokdarwis) pengelola kawasan dapat membuat signage serta peta kawasan wisata secara kreatif dengan menggunakan barang bekas. Selain itu, keberhasilan dengan indikasi berupa tingginya antusiasme peserta. Parameter kesuksesan lainnya dapat dibuktikan dengan aspek kognitif 90\%, aspek afektif $85 \%$, serta aspek konatif $95 \%$.
\end{abstract}

Kata kunci: Kabupaten Lima Puluh Kota, Lembah Harau, peta kawasan, sistem informasi, signage

\begin{abstract}
Signage and destination map is one important information services provided by tourism destination management. Harau Valley is one of the potential tourism destinations in West Sumatra, however it provides less information service to its visitors. To meet the needs of the information services in Harau Valley, a program is held by having a method of community development practice. The approaches being used is participative and educative toward tourism care groups (kelompok sadar wisata). Through the program, the groups are able to make signage and destination maps. The signage was created by the group by using unused material. The outcome of the program shows success with the indications of the high enthusiasm of participants. Based on the finding the enthusiast of the participant is increased as the aspect of cognitive $90 \%$, aspect affective $85 \%$, and conative $95 \%$.
\end{abstract}

Keywords: destination map, Harau valley, information system, Lima Puluh Kota District, signage

\section{PENDAHULUAN}

Kawasan wisata merupakan ruang publik yang memadukan antara bangun ruang atau atraksi alam, manusia atau wisatawan, dan jalan atau akses tempat. Komunikasi antara ketiga elemen ini akan berlangsung dengan baik jika ada suatu informasi baik secara langsung maupun tidak langsung. Komunikasi secara tidak langsung dapat dilakukan dengan menggunakan sistem tanda informasi atau yang disebut dengan sign system. Kawasan wisata yang minim akan keberadaan sign system akan mengakibatkan penumpukan wisatawan di suatu titik. Selain itu hal ini juga berdampak terhadap pola perjalanan wisatawan dalam menentukan arah tujuan di sekitar kawasan wisata tersebut. Sign system dapat membatu wisatawan berinteraksi dengan ruang atau kawasan wisata. Hal ini dikemukakan oleh Tinarbuko (2012) bahwa sign system merupakan suatu rangkaian representasi visual dan simbol grafik yang bertujuan sebagai media interaksi manusia dengan ruang publik. Hal ini menjelaskan bahwa fungsi sign system sebagai penunjuk untuk memudahkan pengunjung atau wisatawan yang berada pada suatu kawasan wisata, sehingga dapat mencari tempat, fasilitas, dan arah dengan mudah dan cepat. Salah satu bentuk sign system di kawasan wisata adalah signage dan peta kawasan. Menurut Fuller (2002), signage dapat membantu seseorang 
mengenal seluk beluk suatu daerah yang baru dengan mudah. Signage adalah sejenis visual grafis dalam ukuran besar yang dibuat untuk menyampaikan informasi pada kalangan audience tertentu (Kusrianto 2010). Signage sebelumnya dikenal dalam bentuk tanda (sign) atau dalam bentuk aksara, seperti petunjuk arah tempat, nama suatu tempat, dan sebagainya. Mengingat pentingnya keberadaan signage serta peta kawasan pada suatu daerah tujuan wisata, kegiatan pengabdian masyarakat ini akan dilaksanakan pada kawasan wisata Lembah Harau.

Salah satu daerah tujuan wisata potensial di Sumatera Barat adalah Lembah Harau yang terletak di Kecamatan Harau, Kabupaten Lima Puluh Kota. Kawasan ini merupakan salah satu cagar alam dengan luas 270,5 ha dan ditetapkan sebagai cagar alam (CA) sejak 10 Januari 1993. Keunggulan kawasan ini adalah potensi alam yang didominasi dengan tebing tinggi dan beberapa air terjun. Potensi ini menjadikan kawasan Lembah Harau sebagai pemenang Green Award dalam kategori A (tatakelola) pada penilaian ISTA (Indonesia Sustainable Tourism Award) 2017 yang diselenggarakan oleh Kementerian Pariwisata RI. Kunjungan wisatawan ke kawasan Lembah Harau juga meningkat setiap tahunnya. Tabel 1 menunjukkan jumlah peningkatan pengunjung yang terjadi di Lembah Harau pada tahun 2011-2015. Pengunjung terbanyak (puncaknya) terjadi pada tahun 2014. Pada tahun 2015 terjadi penurunan pengunjung yang salah satu penyebabnya adalah terlalu ramainya wisatawan di kawasan tersebut sehingga terjadi kemacetan yang sangat panjang.

Lembah Harau berada pada dua nagari, yaitu Nagari Tarantang dan Harau. Hasil observasi lapangan menunjukkan banyaknya signage yang rusak, kurang jelas, dan tidak memiliki kesatuan sistem yang baik dengan potensi alam. Keberadaan signage ini menurut Supriyanto (2008) adalah merupakan media luar ruang yang wujudnya berbentuk tugu atau monumen kecil yang menyatu dengan lingkungan yang ditempatinya. Tidak adanya peta kawasan mengakibatkan wisatawan harus menghentikan kendaraan untuk mencari informasi kepada penduduk setempat. Selain itu, beberapa bangunan fisik tidak memiliki identitas dan signage.

Signage dan peta kawasan selain sebagai penunjuk arah juga berfungsi sebagai informasi identitas kawasan sehingga pengunjung dapat mengenal lebih jauh tentang kawasan. Namun ketika signage tersebut banyak yang rusak maka informasi menjadi tidak efektif bahkan tidak dapat dipahami oleh pengunjung. Saat ini pelayanan informasi berupa petunjuk kawasan di Lembah Harau sangat terbatas dan kurang menarik sehingga banyak informasi yang tidak diketahui oleh wisatawan. Papan petunjuk yang tidak menarik serta tidak teratur juga akan menjadi penyebab dari pencemaran visual yang berdampak kepada keindahan alam di kawasan objek wisata (Gambar 1). Selain itu, hasil wawancara dengan pengelola kawasan yang terdiri atas tiga kelompok sadar wisata (Pokdarwis), yaitu Pokdarwis Sarasah Bunta, Aka Barayun, dan Taman Bermain Anak menyatakan bahwa kurang memahami pentingnya keberadaan signage dan merasa tidak mampu membuat signage atau peta kawasan wisata. Masalah lain yang ditemui pada saat wawancara adalah keterbatasan anggaran pengelola atau Pokdarwis dalam membuat signage dan peta kawasan wisata.

Permasalahan keberadaan signage dan peta kawasan merupakan hal yang perlu dibahas dan diselesaikan dengan melibatkan stakeholder terkait. Perlu perhatian khusus dalam pengembangan signage dan peta kawasan terutama bagi kawasan alam. Signage dan peta kawasan sebaiknya menyatu dengan alam sehingga tidak mengganggu visualisasi alam tersebut. Sebagai bagian dari sarana di kawasan wisata, signage perlu dibuat dengan penuh ketelitian. Selain itu, diperlukan peran serta stakeholder lain yang terkait dalam pembuatan signage. Pengem-

Tabel 1 Data kunjungan wisatawan Lembah Harau (orang)

\begin{tabular}{llcr}
\hline Tahun & Wisnus & Wisman & Jumlah \\
\hline 2011 & 119.027 & 718 & 119.745 \\
2012 & 135.559 & 918 & 136.477 \\
2013 & 152.717 & 2.977 & 155.694 \\
2014 & 160.242 & 3.255 & 163.479 \\
2015 & 106.133 & 1.973 & 108.106 \\
\hline
\end{tabular}

Sumber: Badan Pusat Statistik Kabupaten Lima Puluh Kota pada tahun 2015.

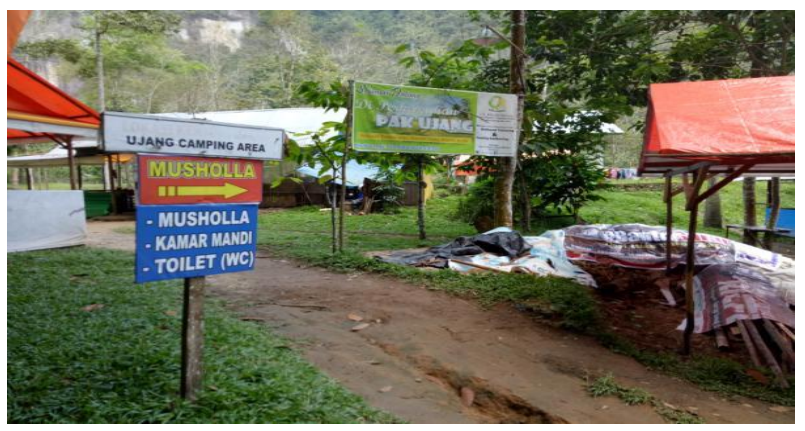

Gambar 1 Contoh signage pada daya tarik wisata alam di Lembah Harau. 
bangan sarana dan prasarana di kawasan alam atau hutan memerlukan kreativitas dan campur tangan aktor ekonomi kreatif yang ada (Putra 2017), sehingga pengelola kawasan tidak bekerja sendiri dan perlu arahan serta bimbingan dari beberapa stakeholder atau instansi terkait. Gabungan stakeholder ini disebut dengan pentahelix yang terdiri atas pemerintah, swasta, akademisi, masyarakat, dan sosial entreprenur (Calzada 2016). Dalam kegiatan ini stakeholder yang terlibat adalah pemerintah, akademisi, masyarakat, dan sosial entreprenur. Metode yang digunakan pada kegiatan ini adalah community development practice, yang dilakukan melalui pendekatan partisipatif dan edukatif. Jika dikaitkan dengan keberadaan pentahelix maka kegiatan ini difasilitasi oleh akademisi dengan melibatkan partisipasi masyarakat dalam hal ini kelompok sadar wisata. Pemerintah bertindak sebagai narasumber dalam kegiatan sosialisasi serta social entreprenur (komunitas seni) sebagai pendamping dalam pembuatan signage dan peta kawasan.

\section{METODE PELAKSANAAN KEGIATAN}

\section{Lokasi dan Partisipan Kegiatan}

Mengingat kawasan Lembah Harau cukup luas maka kegiatan ini akan difokuskan pada lokasi Taman Bermain Anak Nagari Harau. Tempat ini dipilih sebagai lokasi percontohan untuk membuat signage dan peta kawasan karena berada di kawasan Harau dengan sarana prasana cukup lengkap. Peserta pelatihan berasal dari seluruh Pokdarwis yang ada di kawasan Lembah Harau, yaitu Pokdarwis Sarasah Bunta Kanagarian Tarantang, Pokdarwis Aka Barayun Kanagarian Harau, dan Pokdarwis Taman Bermain Anak Kanagarian Harau. Jumlah peserta kegiatan sebanyak 20 orang.

\section{Metode Pelaksanaan Kegiatan}

Kegiatan ini berlangsung selama delapan bulan, yaitu pada bulan April-November 2017 dengan menggunakan metode community development practice serta pendekatan partisipatif dan edukatif. Metode community development practice berorientasi kepada usaha pengembangan pemberdayaan masyarakat dengan menjadikan masyarakat sebagai subjek dan sekaligus objek pembangunan dan melibatkan mereka secara langsung dalam berbagai kegiatan pengabdian masyarakat sebagai upaya meningkatkan peran serta masyarakat dalam pembangunan demi kepentingan mereka sendiri (Vincent 2009). Tahapan dari pelaksanaan kegiatan adalah: pembentukan tim kegiatan, perumusan tujuan kegiatan, identifikasi stakeholder, melakukan kegiatan pemgumpulan data dan analisis kebutuhan kegiatan, penentuan prioritas solusi masalah, persiapan, implementasi berupa penyuluhan dan pelatihan (workshop), pendampingan, review dan evaluasi, serta menentukan kebutuhan dan sasaran baru.

Pendekatan yang dilakukan adalah pendekatan edukatif berupa sosialisasi. Menurut Narwoko \& Suyanto (2009), sosialisasi dapat diartikan sebagai kegiatan penyebarluasan informasi oleh lembaga tertentu kepada masyarakat. Sosialisasi tersebut dapat dilakukan melalui tatap muka secara langsung. Selain pendekatan edukatif, maka pendekatan partisipatif juga dilakukan agar pengelola kawasan wisata dapat terlibat langsung mulai dari perencanaan sampai dengan pembuatan. Peserta diberi kebebasan untuk merencanakan dan membuat signage dalam bentuk pelatihan atau workshop. Menurut Mathis \& Jackson (2002), pelatihan adalah proses di mana seseorang dapat mencapai kemampuan tertentu guna membantu pencapaian tujuan organisasi. Pelatihan memberikan pengetahuan yang spesifik, dapat diketahui, dan keterampilan yang dibutuhkan untuk melaksanakan pekerjaan.

\section{Metode Pengumpulan Data}

Metode pengumpulan data adalah observasi dan wawancara. Menurut Arikunto (2006), observasi adalah mengumpulkan data atau keterangan yang harus dijalankan dengan melakukan usaha-usaha pengamatan secara langsung ke tempat yang akan diselidiki. Kegiatan wawancara adalah usaha mengumpulkan informasi dengan mengajukan sejumlah pertanyaan secara lisan untuk dijawab secara lisan pula. Ciri utama dari wawancara dalah kontak langsung dengan tatap muka antara pencari informasi dengan sumber informasi (Sutopo 2006). Wawancara dilakukan terhadap pengelola objek wisata (Pokdarwis) dan kepala Bidang Sarana Objek Wisata Dinas Pariwisata, Pemuda dan Olah Raga, Kabupaten Lima Puluh Kota.

\section{Pengolahan dan Analisis Data}

Pengolahan dan analisis data dilakukan dengan menggunakan Standar Lothar A. Kreck terhadap sarana prasarana kepariwisataan (Yoeti 1996). Sarana kepariwisataan terbagi atas: a) Sarana pokok kepariwisataan, yaitu sarana yang sangat tergantung kepada arus kedatangan 
orang yang melakukan perjalanan wisata seperti travel agent, hotel, dan jenis akomodasi lainnya, restoran, serta rumah makan lainnya; b) Sarana pelengkap kepariwisataan, yaitu sarana yang menyediakan fasilitas untuk rekreasi yang fungsinya tidak hanya melengkapi sarana pokok tetapi juga dapat menahan lebih lama wisatawan tinggal pada suatu daerah tujuan wisata; c) Sarana penunjang kepariwisataan, yaitu sarana yang menunjang sarana pelengkap dan sarana pokok dan berfungsi tidak hanya membuat wisatawan lebih lama tinggal pada suatu daerah tujuan wisata, tetapi fungsi yang lebih penting adalah agar wisatawan lebih banyak mengeluarkan atau membelanjakan uangnya di tempat yang dikunjungi.

Selanjutnya prasarana terdiri atas dua bagian yang penting, yaitu a) Prasarana perekonomian (economy infrastructures) yang terdiri atas pengangkutan (transportation), komunikasi, kelompok yang termasuk utilitas (penerangan listrik, persediaan air minum, dan sumber energi), dan sistem perbankan, yaitu adanya pelayanan bank atau money changer bagi para wisatawan; b) Prasarana sosial (social infrastructure), yaitu semua faktor yang menunjang kemajuan atau menjamin kelangsungan prasarana perekonomian yang ada seperti pelayanan kesehatan, keamanan, dan petugas yang langsung melayani wisatawan.

\section{HASIL DAN PEMBAHASAN}

\section{Profil Lembah Harau}

Lembah Harau berada $\pm 138 \mathrm{~km}$ dari Padang, $\pm 47 \mathrm{~km}$ dari Bukittinggi, $\pm 18 \mathrm{~km}$ dari Kota Payakumbuh, dan $\pm 2 \mathrm{~km}$ dari pusat kota. Lembah Harau merupakan kawasan wisata alam yang dikelilingi oleh tebing dengan diameter mencapai $400 \mathrm{~m}$, dikelilingi batu pasir yang terjal berwarna-warni dengan ketinggian 100-500 m. Tebing-tebing terjal yang hampir tegak lurus menjulang tinggi dengan bentuknya yang unik mengelilingi lembah. Tebing-tebing terjal tersebut terbentuk dari batuan konglomerat dan batu pasir kuarsa dari formasi brani berumur oligosen (sekitar 38 juta tahun), mempunyai ketinggian 80-300 m. Secara geologi struktur, Lembah Harau yang terjal ini merupakan bidang patahan (sesar), yaitu patahan turun (normal fault) atau patahan naik (thrust fault). Patahan Lembah Harau ini adalah patahan tua yang bersifat tidak aktif hingga saat ini (Nagari Harau 2017). Daerah tujuan wisata di kawasan ini berupa air terjun Sarasah Bunta yang juga berlokasi di kawasan Harau merupakan objek wisata unggulan yang memiliki daya tarik tersendiri. Selain itu, ada air terjun Sarasah Aka Barayun, taman bermain anak, Kampung Eropa, serta pemandangan alam yang indah. Potensi yang tersebar di kawasan Lembah Harau (Ismet 2011) terlihat pada Gambar 2.

Lembah Harau ditetapkan sebagai cagar alam sejak 10 Januari 1993. Cagar alam dan suaka margasatwa Lembah Harau terdapat berbagai spesies tanaman hutan hujan tropis dataran tinggi yang dilindungi, dan sejumlah binatang langka asli Sumatera. Monyet ekor panjang (Macaca fascirulatis) merupakan hewan yang sering terlihat di kawasan ini. Binatang primata lainnya yang hidup di suaka margasatwa ini, seperti siamang (Hylobatessyndactylus) dan simpai (Presbytis melalopos). Suara mereka sering terdengar tapi jarang menampakkan diri. Lembah ini juga didiami oleh spesies kupu-kupu yang bisa terlihat di taman kupu-kupu (Butterfly Garden) yang terletak di tengah-tengah lembah.

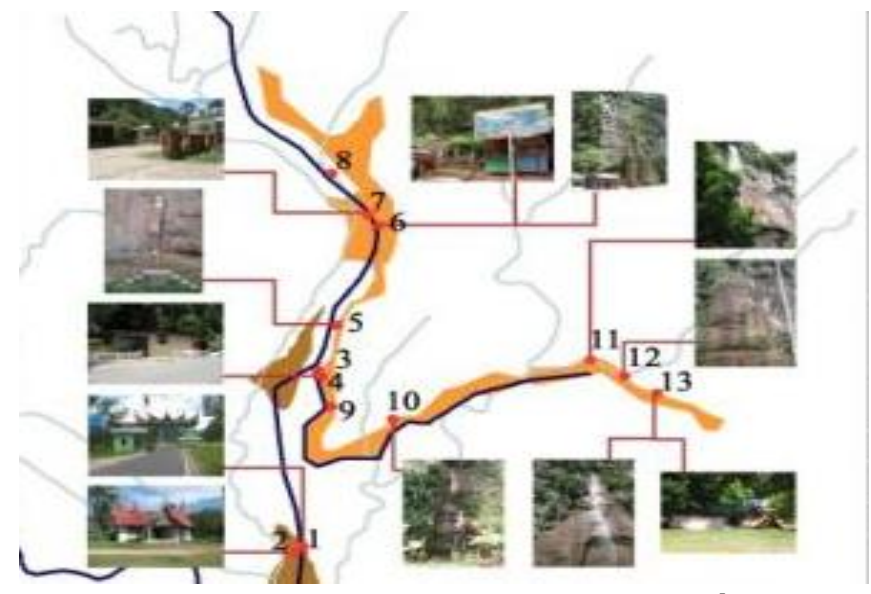

Keterangan:

1. Pintu masuk

2. Dinas kebudayaan dan pariwisata

3. Kantor pusat informasi

4. Kantor resort BKSDA

5. Titik echo

6. Air terjun aka barayun

7. Taman bermain anak

8. Ngalau Amu

9. Air gua

10. Sarasah rupih

11. Air Lulus

12. Sarasah Bunta

13. Sarasah Murai

Sumber: Ismet (2011)

Gambar 2 Peta kawasan Lembah Harau. 


\section{Identifikasi Stakeholder}

Setelah dilakukan pembentukan tim kegiatan serta perumusan tujuan kegiatan maka dilakukan identifikasi stakeholder yang terlibat pada kegiatan ini. Hasil kunjungan ke lapangan maka stakeholder yang terlibat adalah masyarakat dan pengelola kawasan serta Pokdarwis, pengunjung, staff kantor Wali Nagari Harau dan Wali Nagari Tarantang, Camat Harau, serta Kepala Bidang Destinasi, Kantor Dinas Pemuda, Olahraga, dan Pariwisata Kabupaten Lima Puluh Kota. Mengingat kawasan Harau adalah kawasan hutan lindung maka perlu juga berkoordinasi dengan balai konservasi sumber daya alam (BKSDA). Setelah diidentifikasi stakeholder yang potensial terlibat maka dilakukan interview. Selain kegiatan wawancara terhadap masing-masing stakeholder, observasi juga dilakukan agar dapat menyinkronkan permasalahan yang ada. Berdasarkan hasil interview dan observasi didapat bahwa keberadaan signage sangat kurang dan peta kawasan wisata belum ada.

Kegiatan pembuatan signage dan peta kawasan difokuskan pada taman bermain anak sebagai contoh bagi pengelola atau Pokdarwis yang berasal dari kawasan Lembah Harau lainnya, hal ini disebabkan kawasan Lembah Harau cukup luas. Pokdarwis lain dapat mengaplikasikannya pada daerah masing-masing dengan adanya percontohan di taman bermain anak.

\section{Implementasi Kegiatan}

Implementasi kegiatan berupa kegiatan sosialisasi atau penyuluhan. Sebelum kegiatan ini dilakukan maka diadakan pre-test untuk mengetahui pengetahuan peserta terhadap pelayanan informasi di daerah tujuan wisata. Setelah pretest maka dilakukan penyuluhan atau sosialisasi tentang pentingnya pelayanan informasi pada daerah tujuan wisata. Pada kegiatan ini materi diberikan oleh pihak pemerintah dan akademisi dengan judul materi "peranan kelompok sadar wisata terhadap pengelolaan kawasan wisata" dan "pelayanan informasi wisata kreatif di daerah tujuan wisata" (Gambar 3).

Setelah kegiatan sosialisasi peserta diminta untuk mengidentifikasi sarana parasarana yang ada di taman bermain anak agar dapat diterjemahkan ke dalam bentuk peta kawasan serta pembuatan signage. Hasil wawancara dan observasi pada lokasi percontohan, yaitu taman bermain anak maka sarana dan prasarana dikelompokkan seperti seperti pada Tabel 2 .

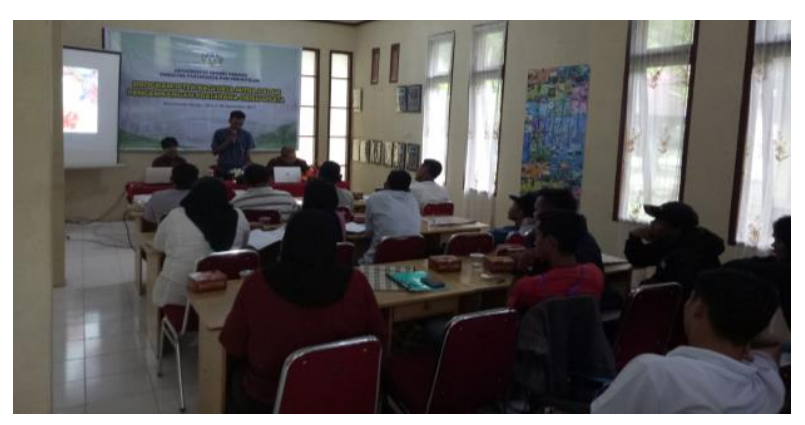

Gambar 3 Kegiatan sosialisasi dan workshop.

Tabel 2 Sarana prasarana taman bermain anak

\begin{tabular}{ll}
\hline \multicolumn{1}{c}{ Kriteria } & \multicolumn{1}{c}{ Nama/jenis } \\
\hline Objek & Pemandangan Lembah \\
& Harau \\
& Flora: Anggrek Harimau \\
& Fauna: tukan toco dan buaya \\
Akses & Jalan \\
& Jembatan \\
& Tempat parkir \\
Akomodasi & Warung jajanan, toilet, \\
Fasilitas & dermaga bebek air, gazebo, \\
& shelter, plaza, taman bunga, \\
& taman kupu-kupu, fountain, \\
& patung rusa, patung harimau, \\
dan rumah pohon \\
Transportasi & Kendaraan pribadi \\
Catering service & Warung makan \\
Aktivitas rekreasi & Permaianan anak \\
& Permainan bebek air \\
Komunikasi & - \\
Sistem perbankan & - \\
Kesehatan & - \\
Keamanan & Pos keamanan \\
Kebersihan & Tempat sampah \\
Sarana ibadah & Tempat sholat \\
Sarana pendidikan & - \\
Sarana olah raga & Jalur jogging, kolam renang \\
& anak, dan sepeda air \\
\hline
\end{tabular}

Agar lebih menarik maka peserta sepakat untuk menentukan icon dari kawasan bermain anak tersebut. Setelah dilakukan diskusi bersama maka dipilih bunga anggrek harimau sebagai icon. Hal ini disebabkan karena anggrek harimau adalah salah satu flora langka di kawasan Lembah Harau. Bunga anggrek harimau di simbolisasikan menjadi image cartoon seperti pada Gambar 4 karena penempatan peta tersebut berada pada lokasi permainan anak.

Selanjutnya untuk kegiatan pelatihan atau workshop yang diadakan adalah mengenalkan kepada kelompok sadar wisata bahwa pelayanan informasi berupa signage yang dibutuhkan pada objek wisata dapat dibuat secara kreatif dengan 


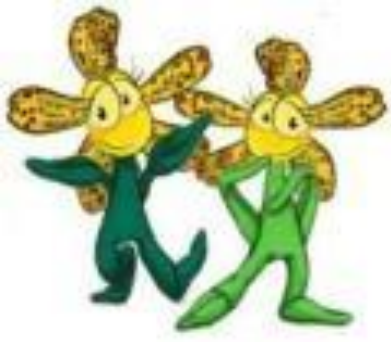

Gambar4 Icon kawasan dalam prototype peta kawasan.

menggunakan bahan atau barang bekas seperti kayu, plastik, sandal bekas atau barang elektronik yang tidak terpakai. Pelatihan ini didampingi oleh kelompok seni dengan spesifikasi seni rupa. Peserta diberi kebebasan dalam pelatihan tersebut untuk membawa barang bekas yang ada di sekitar rumah. Peserta dibagi atas tiga kelompok dan masing-masing kelompok membuat konsep signage yang ingin mereka tampilkan. Instruktur bertugas memantau serta memberikan masukan dalam hal membuat konsep, teknik pewarnaan, dan perekatan bahan yang digunakan.

Hasil dari kegiatan pelatihan dan workshop tersebut adalah contoh dan model signage serta peta kawasan yang ada pada kawasan permainan anak di Nagari Harau (Gambar 5). Konsep peta kawasan percontohan adalah gambaran umum kawasan dengan icon clip art pada setiap fasilitas dan objek yang ada. Icon clip art yang disusun pada peta kawasan merupakan hasil observasi semua peserta (Gambar 6). Selanjutnya, pembuatan signage dipilih bahan dasar kayu dengan petunjuk arah beberapa fasilitas pilihan seperti toilet dan musholla.

\section{Evaluasi}

Pelatihan dan workshop yang dilakukan telah berhasil membuka peluang kreativitas bagi kelompok sadar wisata yang ada di kawasan Lembah Harau, Kabupaten Lima Puluh Kota. Materi serta teori-teori yang diberikan diseleksi dan diterjemahkan dengan menggunakan bahasa yang sederhana agar dapat dipahami oleh peserta. Hal tersebut sesuai dengan pendapat Rustanto (2016) bahwa dalam proses pelatihan yang disisipi dengan materi harus disampaikan dengan hasil yang dapat merubah cara berpikir peserta yang harus ditekankan berupa keinginan untuk belajar, siap belajar, dan alasan tetap mau belajar. Guna untuk mengetahui efektivitas penyampaian materi yang dilakukan maka dilakukan uji pre-test dan post-test. Tujuan dari ujian ini adalah untuk mengetahui sejauh mana proses hasil pembelajaran yang disampaikan
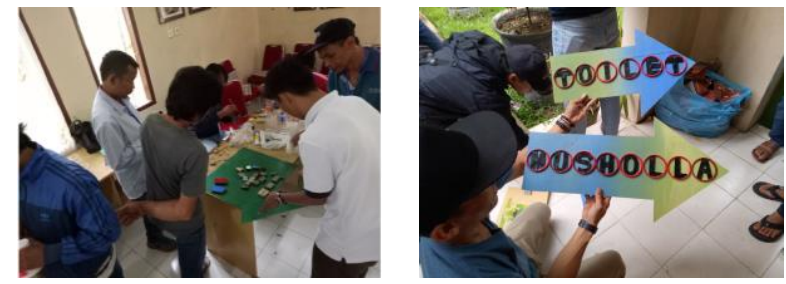

Gambar 5 kegiatan workshop pembuatan signage dan peta kawasan.
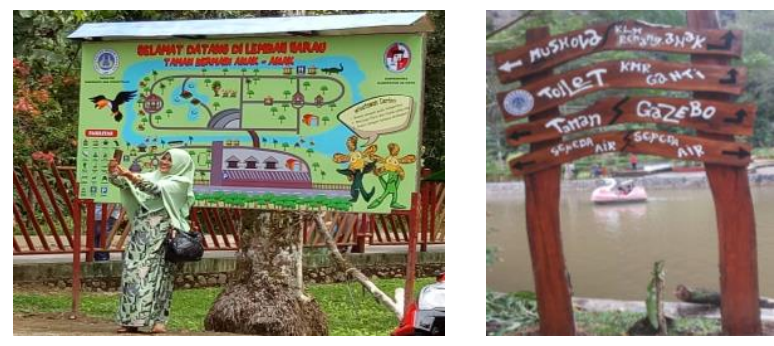

Gambar 6 Prototype peta kawasan dan signage.

oleh pemateri terhadap peserta. Adapun hasil tes pengetahuan mengenai konsep dasar komunikasi efektif terlihat pada Tabel 3.

Berdasarkan data Tabel 3 terlihat bahwa secara kuantitatif pengetahuan peserta mengenai pelayanan informasi berupa peta kawasan dan signage sebesar $10 \%$ pada awal dilakukan pelatihan, namun setelah dilakukan penyampaian materi pengetahuan peserta meningkat menjadi 90\%. Aspek afektif, posisi hasil pre-test menunjukkan sebesar $10 \%$ yang artinya peserta masih menganggap bahwa pelatihan sebagai formalitas instansi. Setelah penyampaian materi, nilai post-test yang dihasilkan cukup signifikan meningkat sebesar $85 \%$ yang menyatakan bahwa perlu dilakukan pelatihan. Sedangkan, untuk penilaian pre-test mengenai aspek konatif, nilai peserta hanya sebesar 5\% yang menyatakan bisa membuat pelayan informasi kreatif berupa signage dan peta kawasan wisata. Sedangkan sebesar 95\% hasil post-test menunjukkan ada peningkatan yang besar dan antusias masyarakat dalam kegiatan pelayanan informasi kreatif di kawasan wisata.

\section{SIMPULAN}

Pelayanan informasi kreatif di kawasan wisata dirasa sangat perlu bagi pengunjung yang berada di objek wisata. Salah satu bentuk pelayanan informasi tersebut adalah signage dan peta kawasan. Selain berfungsi sebagai media informasi signage dan peta kawasan menjadi salah satu daya tarik di kawasan wisata jika keberadaannya secara kreatif terkonsep dan menyatu dengan 
Tabel 3 Hasil uji pre-test dan pos-test

\begin{tabular}{lcccccc}
\hline \multirow{2}{*}{\multicolumn{1}{c}{ Kegiatan }} & \multicolumn{3}{c}{ Pre-test (20 orang) } & \multicolumn{3}{c}{ Post-test (20 orang) } \\
\cline { 2 - 7 } & $\begin{array}{c}\text { Setuju } \\
(\%)\end{array}$ & $\begin{array}{c}\text { Cukup } \\
(\%)\end{array}$ & $\begin{array}{c}\text { Tidak setuju } \\
(\%)\end{array}$ & $\begin{array}{c}\text { Setuju } \\
(\%)\end{array}$ & $\begin{array}{c}\text { Cukup } \\
(\%)\end{array}$ & $\begin{array}{c}\text { Tidak setuju } \\
(\%)\end{array}$ \\
\hline Aspek kognitif (mengetahui) & 10 & 30 & 60 & 90 & 10 & 0 \\
Aspek afektif (merasa perlu) & 10 & 60 & 30 & 85 & 15 & 0 \\
Aspek konatif (dapat melakukan) & 5 & 70 & 25 & 95 & 5 & 0 \\
\hline
\end{tabular}

keadaan di sekitar dalam hal ini daerah tujuan wisata alam. Hal ini menjadi pengetahun baru bagi pengelola kawasan wisata atau Pokdarwis yang ada di kawasan Lembah Harau. Selain menjadi pengetahuan yang bermanfaat, peserta juga dapat membuat media informasi berupa signage dari barang-barang bekas. Begitu juga dengan pembuatan peta kawasan, peserta dapat menuangkan ide kreatif melalui icon serta clip art. Oleh karena itu, peserta yang terdiri atas anggota Pokdarwis di kawasan Lembah Harau merasa perlu kegiatan ini dilakukan.

Agar keberlangsungan kegiatan pelayanan informasi kreatif pada daya tarik wisata alam Lembah Harau, Kabupaten Lima Puluh Kota semakin maksimal maka diperlukan peran serta stakeholder lainnya seperti pihak swasta yang dapat memfasilitasi kelompok sadar wisata kawasan Lembah Harau dengan media pelayanan informasi yang lebih baik. Selain itu perlu kontrol yang lebih intensif dari kelompok sadar wisata terhadap media pelayanan informasi tersebut agar keberadaannya terjaga serta kerusakan dapat ditanggulangi dengan cepat.

\section{DAFTAR PUSTAKA}

Arikunto S. 2006. Metode Penelitian Kualitatif. Jakarta (ID): Bumi Aksara.

Calzada I. 2016. (Un) Plugging Smart Cities with urban transformations: towards multistakeholder city-regional complex urbanity?. URBS, Revista de Estudios Urbanos y Ciencias. 6(2): 25-45.

Fuller G. 2002. The Arrow-Directional Semiotics: Wayfinding in Transit. Social Semiotics. 12(3): 231-244. 10350330216376 https://doi.org/10.1080/

Ismet Y. 2011. Ekowisata di Kawasan Taman Wisata Alam Lembah Harau, Sumatera Barat. [Thesis]. Bogor (ID): Institut Pertanian Bogor.
Kusrianto A. 2010. Pengantar Tipografi. Jakarta (ID): PT. Elex Media Komputindo.

Mathis RL, Jackson JH. 2002. Manajemen Sumberdaya Manusia (terjemahan). Edisi Pertama. Buku dua. Jakarta (ID): Salemba Empat.

Nagari Harau. 2017. Profil Nagari Harau. Pemerintahan Kabupaten Lima Puluh Kota. Nagari Harau (ID): Kecamatan Harau.

Narwoko JD, Suyanto B. 2011. Sosiologi Teks dan Pengantar Terapan. Edisi Keempat. Jakarta (ID): Kencana

Putra T. 2017. Ekonomi Kreatif dan Daya Tarik Objek Wisata Studi Kasus Objek Wisata Sikayan Balumuik Kecamatan Pauh Kota Padang. Jurnal Pendidikan dan Keluarga. 9(1): 36-44. https://doi.org/10.24036/ jpk/vol9-iss1/43

Rustanto B. 2016. Masyarakat Multikultur di Indonesia. Bandung (ID): PT. Remaja Rosda Karya.

Supriyanto S. 2008. Meraih Untung dari Spanduk hingga Billboard. Yogyakarta (ID): Pustaka Grhatama.

Sutopo HB. 2006. Metode Penelitian Kualitatif. Surakarta (ID): UNS Press.

Tinarbuko S. 2012. Semiotika Komunikasi Visual. Yogyakarta (ID): Jalasutra.

Yoeti OA. 1996. Pengantar Ilmu Pariwisata. Bandung (ID): Angkasa

Vincent IIJW (Jack). 2009. Community development practice. In Philips R, Pittman RH (Editor). An Introduction to Community Development. Page: 58-74. New York (US): Routledge. 